\title{
A Quantitative Factorial Component Analysis to Investigate the Recent Changes of Japan's Weight-Based Food Self-Sufficiency Ratio
}

\author{
Kunihisa Yoshii ${ }^{1}$, Tatsuo Oyama ${ }^{2}$ \\ ${ }^{1}$ Ministry of Agriculture, Forestry and Fisheries (MAFF), Tokyo, Japan \\ ${ }^{2}$ National Graduate Institute for Policy Studies (GRIPS), Tokyo, Japan \\ Email: oyamat@grips.ac.jp
}

Received 24 November 2015; accepted 22 January 2016; published 26 January 2016

Copyright (C) 2016 by authors and Scientific Research Publishing Inc.

This work is licensed under the Creative Commons Attribution International License (CC BY). http://creativecommons.org/licenses/by/4.0/

(c) (i) Open Access

\begin{abstract}
We investigate the weight-based food self-sufficiency ratio (WSSR) for Japan over a 50-year period (1961-2011) by applying factorial component analysis technique in order to measure the changes of the WSSR quantitatively. Quantitative data analysis is employed to determine the drivers of those changes. Numerical results show that Japan experienced a drastic decline in its food selfsufficiency ratio (FSSR) during the above period. The factorial component analysis shows that such a decline was caused by the changes in the FSSR of the food groups/items, not in the quantity of the food supply. A number of characteristics of those changes are presented and a list of major food groups that have major impacts on the changes is constructed. The findings in this paper reiterate the alarming food security problem in Japan and provide clear insight into the causes of this problem. The findings in this study pick up where previous studies have left off, aid the food-related policy-making process and identify new ideas for future food research.
\end{abstract}

\section{Keywords}

Food Self-Sufficiency Ratio, Food Security, Factorial Component Analysis

\section{Introduction}

"Food security" is an important issue in Japan. This is partly due to the surge in world food and agricultural commodity prices in 2007, but it also reflects the food supply insufficiency the country has experienced over the 
past few decades. "Food security” is a multi-faceted and complex term, with varied applications. Indeed, among scholars and more broadly in the government, "food security" is used to refer to different concepts and contexts. The most widely used definition that was agreed upon by the Food and Agriculture Organization (FAO) of the United Nations was adopted in 1996 by representatives from over 180 countries, including Japan, with the Rome Declaration on World Food Security: "Food security exists when all people, at all times, have access to sufficient, safe and nutritious food to meet their dietary needs and food preferences for an active and healthy life"1. However, this definition allows for a range of interpretations and applications, depending on the purpose of the user. In developing countries, food insecurity may be a matter of life or death. In developed countries, food insecurity may create political riots and pressure national security and sovereignty. The rice replacement program in Japan in the after-war period is but one example.

Living in the world's third largest economy, Japanese enjoy a standard of living that most people in the world can only dream of. However, even though Japan is a prosperous nation, and Japanese have enough food to lead "an active and healthy life", it is widely believed in Japan that the country has a problem that is theoretically faced only by the world's poorer countries: food insecurity. Although this may sound ironic, even contradictory, some Japanese worry about an excessive nutritional intake of animal fats and unbalanced diet, many worry about Japan's future food supply as its food self-sufficiency ratio (FSSR) has been declining over the past half century.

The FSSR is used to represent the magnitude of domestic production as a proportion of domestic utilization (including consumption). It is defined as the percentage of domestic production against domestic utilization. On a calorie basis, Japan's FSSR has drastically dropped from 79\% in 1960 to 39\% in 2005, a drop of 40 percentage points in 45 years. This trend was publicly noted in 1973 and has been documented by Ogura [1], Higuchi [2] and Saeki [3], and more recently by, among others, Kako [4], Tanaka and Hosoe [5], Mashimo [6], Yoshii and Oyama [7], Trung, et al. [8], Hayami and Godo [9], Hayami [10], and in various reports issued by Japan's Ministry of Agriculture, Forestry and Fisheries(MAFF) (2000-2008) [11].

These studies focus on the exogenous elements that are factors of the decline of Japan's WSSR and economic implications both for supply and demand of food. Many have given attention to domestic and international economic policies. However, few have examined the endogenous factors that account for the downward trend in the FSSR. It is important, though, to investigate the drastic change in Japan's FSSR in more detail, from the inside out in order to gain an overall understanding of the situation. Such research would help policy makers in planning new directions for the country's future food supply and food policy.

We seek to enrich the literature by performing quantitative factorial component analysis to investigate, in detail, the endogenous elements that have affected Japan's WSSR over the 50 years from 1961 to 2011 . In the next section the paper starts by constructing and presenting a weight-based WSSR for Japan. Then in Section 3 the ratio will then be decomposed into factorial components for quantitative analysis. The characteristics of the changes will be analyzed to provide insights into the most important factors that have driven down Japan's WSSR. The findings, which are presented in Section 4, will have implications for policy directions. Summary and conclusions are given in the final Section 5.

\section{Japan's Food Self-Sufficiency Ratio and Its Past Trend}

Calorie intake is often used in Japan as the basis for calculating the nation's FSSR. The FSSR on a calorie basis is defined as the percentage of the net calorie intake per capita per day supplied by domestic production over the total net calorie intake per capita per day. Japan's FSSR on a calorie basis drastically fell from $79 \%$ in 1960 to 39\% in 2005 (Kako [4]), and has stayed around 39\% thereafter until now. These figures, with minor adjustments, were widely used in academic papers and policy discussions in MAFF (various reports/papers 2007-2009), Kako [4], Tanaka and Hosoe [5], Mashimo [6], Yoshii and Oyama [7], Trung, et al. [8].

There are other methods to measure a country's FSSR. One measure using weight is called the "WSSR on a weight basis" (WSSR). Similarly, the FSSR measure based on money is called the "FSSR on a monetary basis" (MSSR). Japanese make little use of the MSSR while the WSSR is rarely given official attention in Japan. Japanese government, however, has announced the target for the FSSR on a calorie basis as $45 \%$ in 2025 even though it seems to be very difficult to be attained as the current value is still low as of 39\% in 2014 .

${ }^{1}$ FAO, “Rome Declaration on World Food Security and World Food Summit Plan of Action”, World Food Summit, Rome, 13-17 November 1996. 
This paper, however, opts to use a more internationally recognized approach to calculate Japan's FSSR so that a comparative perspective may be obtained. This paper employs FAO definitions and utilizes its Food Balance Sheets to reassess Japan's data from 1961 to 2011 so that a comprehensive picture of the country's food supply patterns during that period can be obtained. Data for those sheets were standardized and updated in December 2009. We have used the most recent data set FAO-STAT as the 2011 data is the latest one at this stage.

Using the FAO's internationally acknowledged methods of data classification for representing actual agricultural production, a measure of Japan's FSSR on a weighted basis (hereinafter, the "WSSR") is developed to estimate the magnitude of domestic production in relation to overall domestic utilization. Let $N$ be the set of food groups/items concerned. Then Japan's FSSR, on a weight basis, denoted by WSSR, is formulated as follows:

$$
W S S R=\frac{\sum_{i \in N} D P_{i}}{\sum_{i \in N} D P_{i}+\sum_{i \in N} I M_{i}+\sum_{i \in N} S V_{i}-\sum_{i \in N} E X_{i}}
$$

where

\begin{tabular}{ccc}
\hline$D P_{i}$ & $:$ & Domestic production of food group/item $i$ (ton), $i \in N ;$ \\
$I M_{i}$ & $:$ & Imports of food group/item $i$ (ton), $i \in N ;$ \\
$S V_{i}$ & $:$ & Stock variation (increase or decrease) of food group/item $i$ (ton), $i \in N ;$ \\
$E X_{i}$ & $:$ & Exports of food group/item $i$ (ton), $i \in N$, \\
\hline
\end{tabular}

While (1) is used to obtain a value for the FSSR of all food groups/items, the self-sufficiency ratio of each food group/item $i$ on a weight basis (\%), denoted by $W S S R_{i}$, can also be calculated in a similar manner.

$$
W S S R_{i}=\frac{D P_{i}}{D P_{i}+I M_{i}+S V_{i}-E X_{i}}, \quad i \in N .
$$

Likewise, a food import dependency ratio for Japan (the “FIDR”) on a weight basis (\%) is developed to assess the importance of imported food in the country. The FIDR expresses the magnitude of imports in relation to domestic utilization and is formulated in a similar manner to its WSSR counterpart except for the difference in the numerator, where domestic production is replaced by the value for import, as follows.

$$
F I D R=\frac{\sum_{i \in N} I M_{i}}{\sum_{i \in N} D P_{i}+\sum_{i \in N} I M_{i}+\sum_{i \in N} S V_{i}-\sum_{i \in N} E X_{i}} .
$$

The numerical results for WSSR and FIDR were derived by computing the values for (1), (2) and (3) using the FAO 2010 data for Japan’s Food Balance Sheets from 1961 to 2011. The values are given in Table 1 and graphed in Figure 1. Twenty major food groups (MFG) were used to compute the ratio. The group labeled "Miscellaneous" is omitted due to missing data throughout the reference period". The use of all 20 MFG allows for a consistent measure of the total food supply and utilization in the country. These MFG and the food items included in each grouping are given in Table 2.

The results show that the values for both the WSSR and the FIDR changed drastically over time in ways consistent with the views of those concerned about Japan's future food supply and import dependency. It is obvious from the graph in Figure 1 that the values for the WSSR fell sharply from 87\% in 1961 (or an average of 80\% in the 60 s) to an average of $54 \%$ in the first five years of the new millennium. It is a drop of nearly 34 percentage points in 45 years, or a loss of 39\% in value. The values for FIDR rose from just above 14\% in 1961 to more than $49 \%$ in 2005. That is an increase of 35 percentage points over the same period, or a 2.5 -fold gain in value. In the meantime, food supply in Calories (kcal) continued to rise as Japanese sought a higher living standard and the economy grew. The calorie intake rose from 2468 Calories per capita per day in 1961 to 2752 Calories in

\footnotetext{
${ }^{2}$ The major food groups were: (1) Cereals-Excluding Beer; (2) Starchy Roots; (3) Sugar Crops; (4) Sugar \& Sweeteners; (5) Pulses; (6) Tree Nuts; (7) Oil Crops; (8) Vegetable Oils; (9) Vegetables; (10) Fruits-Excluding Wine; (11) Stimulants; (12) Spices; (13) Alcoholic Beverages (14) Meat; (15) Offals; (16) Animal Fats; (17) Eggs; (18) Milk-Excluding Butter; (19) Fish, Seafood; and (20) Aquatic Products, Other.
} 
Table 1. WSSR and FIDR on a weight basis (\%), and Food supply (kcal/capita/day) (kcal), Japan 1961-2011.

\begin{tabular}{|c|c|c|c|c|c|c|c|c|c|c|}
\hline & 1961 & 1962 & 1963 & 1964 & 1965 & 1966 & 1967 & 1968 & 1969 & 1970 \\
\hline WSSR $(\%)$ & 86.4 & 84.8 & 82.2 & 79.9 & 80.0 & 77.5 & 77.7 & 77.2 & 74.7 & 72.3 \\
\hline FIDR $(\%)$ & 15.0 & 15.9 & 19.2 & 21.6 & 23.2 & 24.6 & 25.5 & 26.1 & 27.4 & 30.4 \\
\hline \multirow[t]{2}{*}{ Food supply (kcal) } & 2525 & 2572 & 2609 & 2632 & 2621 & 2643 & 2690 & 2700 & 2699 & 2738 \\
\hline & 1971 & 1972 & 1973 & 1974 & 1975 & 1976 & 1977 & 1978 & 1979 & 1980 \\
\hline WSSR $(\%)$ & 71.2 & 70.7 & 68.8 & 67.9 & 68.6 & 66.2 & 66.0 & 65.7 & 64.9 & 63.8 \\
\hline FIDR $(\%)$ & 29.6 & 30.5 & 33.2 & 34.5 & 33.0 & 35.7 & 36.0 & 36.5 & 37.4 & 36.8 \\
\hline \multirow[t]{2}{*}{ Food supply (kcal) } & 2729 & 2782 & 2773 & 2743 & 2717 & 2752 & 2774 & 2791 & 2808 & 2799 \\
\hline & 1981 & 1982 & 1983 & 1984 & 1985 & 1986 & 1987 & 1988 & 1989 & 1990 \\
\hline WSSR $(\%)$ & 64.9 & 65.6 & 64.8 & 65.2 & 64.0 & 63.7 & 62.5 & 61.4 & 61.4 & 60.8 \\
\hline FIDR $(\%)$ & 36.3 & 35.9 & 36.7 & 37.7 & 38.4 & 38.1 & 38.9 & 40.8 & 40.0 & 40.3 \\
\hline \multirow[t]{2}{*}{ Food supply (kcal) } & 2750 & 2814 & 2829 & 2827 & 2862 & 2874 & 2896 & 2942 & 2969 & 2949 \\
\hline & 1991 & 1992 & 1993 & 1994 & 1995 & 1996 & 1997 & 1998 & 1999 & 2000 \\
\hline WSSR $(\%)$ & 58.8 & 58.5 & 56.9 & 57.2 & 55.6 & 55.3 & 55.4 & 54.7 & 54.0 & 53.6 \\
\hline FIDR $(\%)$ & 41.9 & 42.4 & 43.6 & 44.7 & 45.9 & 45.5 & 46.0 & 45.7 & 47.3 & 48.0 \\
\hline \multirow[t]{2}{*}{ Food supply (kcal) } & 2934 & 2943 & 2926 & 2932 & 2921 & 2963 & 2939 & 2895 & 2898 & 2900 \\
\hline & 2001 & 2002 & 2003 & 2004 & 2005 & 2006 & 2007 & 2008 & 2009 & 2010 \\
\hline WSSR $(\%)$ & 53.1 & 52.5 & 52.2 & 52.1 & 52.2 & 51.7 & 52.8 & 53.5 & 52.7 & 51.4 \\
\hline FIDR $(\%)$ & 47.7 & 48.4 & 48.3 & 49.1 & 49.5 & 49.7 & 48.4 & 48.4 & 47.4 & 49.8 \\
\hline \multirow[t]{2}{*}{ Food supply (kcal) } & 2890 & 2853 & 2842 & 2843 & 2828 & 2777 & 2816 & 2732 & 2674 & 2692 \\
\hline & 2011 & & & & & & & & & \\
\hline WSSR $(\%)$ & 51.3 & & & & & & & & & \\
\hline FIDR $(\%)$ & 49.9 & & & & & & & & & \\
\hline Food supply (kcal) & 2719 & & & & & & & & & \\
\hline
\end{tabular}

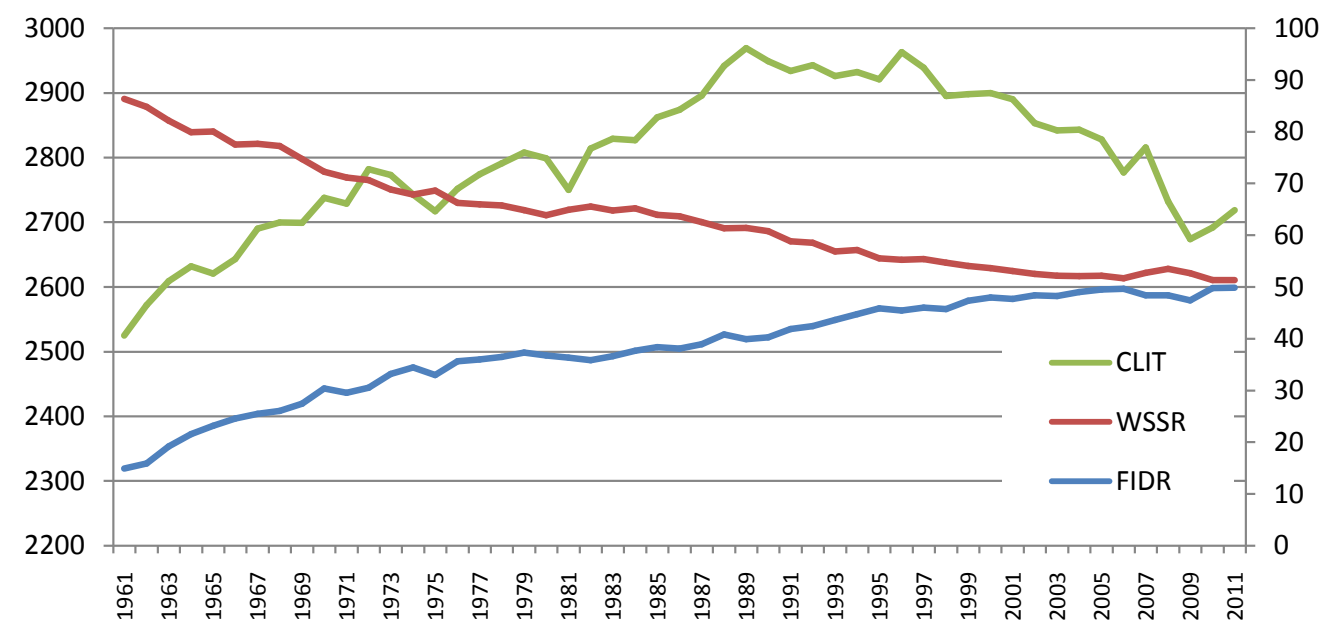

Figure 1. Japan's per capita per day calorie intake (left axes) and WSSR, FIDR (right axes).

1972, peaking at 2859 Calories in 1996 before slightly decreasing to 2743 Calories in 2005 . That was a $11 \%$ increase in daily calorie intake over the last half century. Nevertheless, the 2005 level was just about that of the early 1970s, implying no net improvement in calorie intake over the 35-year period.

Taken altogether, the three trends indicate that while the quality of life is improving, Japan produces only half of its food needs and has come to depend on foreign imports for the other half. Setting aside differences in the 
Table 2. 20 MFG and the items included.

\begin{tabular}{|c|c|}
\hline MFG & Items included \\
\hline Cereals-Excluding Beer & Wheat; Rice (Milled Equivalent); Barley; Maize; Rye; Oats; Millet; Sorghum; Cereals, Other. \\
\hline Starchy Roots & Cassava; Potatoes; Sweet Potatoes; Yams; Roots, Other. \\
\hline Sugar Crops & Sugar Cane; Sugar Beet. \\
\hline Sugar \& Sweeteners & Sugar, Non-Centrifugal; Sugar (Raw Equivalent); Sweeteners, Other; Honey. \\
\hline Pulses & Beans; Peas; Pulses, Other. \\
\hline \multicolumn{2}{|l|}{ Tree Nuts } \\
\hline Oil Crops & $\begin{array}{l}\text { Soyabeans; Groundnuts (Shelled Equation); Sunflowerseed; Rape and Mustardseed; Cottonseed; } \\
\text { Coconuts-Incl Copra; Sesameseed; Palmkernels; Olives; Oilcrops, Other. }\end{array}$ \\
\hline Vegetable Oils & $\begin{array}{l}\text { Soyabean Oil; Groundnut Oil; Sunflowerseed Oil; Rape and Mustard Oil; Cottonseed Oil; } \\
\text { Palmkernel Oil; Palm Oil; Coconut Oil; Sesameseed Oil; Olive Oil; Ricebran Oil; Maize Germ } \\
\text { Oil; Oilcrops Oil, Other. }\end{array}$ \\
\hline Vegetables & Tomatoes; Onions; Vegetables, Other. \\
\hline Fruits-Excluding Wine & $\begin{array}{l}\text { Oranges, Mandarines; Lemons, Limes; Grapefruit; Citrus, Other; Bananas; Plantains; Apples; } \\
\text { Pineapples; Dates; Grapes; Fruits, Other }\end{array}$ \\
\hline Stimulants & Coffee; Cocoa Beans; Tea. \\
\hline Spices & Pepper; Pimento; Cloves; Spices, Other. \\
\hline Alcoholic Beverages & Wine; Beer; Beverages, Fermented; Beverages, Alcoholic; Alcohol, Non-Food. \\
\hline Meat & Bovine Meat; Mutton \& Goat Meat; Pig Meat; Poultry Meat; Meat, Other. \\
\hline \multicolumn{2}{|l|}{ Offals } \\
\hline Animal Fats & Butter, Ghee; Cream; Fats, Animals, Raw; Fish, Body Oil; Fish, Liver Oil. \\
\hline \multicolumn{2}{|l|}{ Eggs } \\
\hline \multicolumn{2}{|l|}{ Milk-Excluding Butter } \\
\hline Fish, Seafood & $\begin{array}{l}\text { Freshwater Fish; Demersal Fish; Pelagic Fish; Marine Fish, Other; Crustaceans; Cephalopods; } \\
\text { Molluscs, Other. }\end{array}$ \\
\hline Aquatic Products, Other & Meat, Aquatic Mammals; Aquatic Animals, Others; Aquatic Plants. \\
\hline Miscellaneous & \\
\hline
\end{tabular}

statistics used, the results correspond to the findings described in the MAFF papers and in the previous studies by Kako [4], Tanaka and Hosoe [5], Mashimo [6], Yoshii and Oyama [7], Trung, et al. [8], Hayami and Godo [9], and Hayami [10].

Whether the trends are cause for "alarm” depends on one’s point of view. Many other variables also shape the political decision-making process in this globalized era. One could say that these trends might raise much concerns in both domestic and international arenas, given their impact both on Japan's food production, prices and trade, and the world's needs for overall global sufficiency.

In addition to realizing the changes in both WSSR, FIDR and calorie intake, one should also note that the pattern of food consumption in Japan has changed considerably over the past 50 years. Mashimo [6] has commented on the reasons for such changes ${ }^{3}$, and studied three different patterns of Japanese food consumption in 2005. The first pattern was the status quoin 2005. The second pattern was a set of food intake and nutritional data recommended by the Ministry of Health, Welfare and Labor (MHWL). This pattern has been created as the ideal for Japanese to maintain their health, avoiding lifestyle-related sickness (MHWL pattern). And the third pattern was a set of food requirements based on the daily meal menus organized by Setsuko Shirone, an expert of sustainable food consumption and organic agriculture. Mashimo [6] called this the Chisan-chisho pattern (LP-LC pattern), after a popular movement that encouraged local production and local consumption in Japan. In 2005, according to the MHWL pattern, the ingestion of grains, potatoes and vegetables would increase, while the consumption of meat, milk products, sugar and fat would drastically decrease. This tendency was even more radical in the LP-LC pattern. The difference was the high amount of marine product intakes that was still considered to be possible. All of this, however, consisted of small fish and coastal fish, as well as the continued con-

\footnotetext{
${ }^{3}$ Mashimo argued that dietary changes in Japan dated back to the 1960s and 1970s with the rice diversion program and the "westernization" of the Japanese dietary habit. See Mashimo (2008) for details.
} 
sumption of other domestically available marine species (Mashimo [6]).

\section{Method and Numerical Results for Factorial Component Changes}

\subsection{Method for Measuring Changes}

This part of the paper employs a factorial component analysis to assess the weight of endogenous factors that might account for the decline in the WSSR. The annual total change in the WSSR is broken into two major factorial components: (1) the change due to the WSSR change of each MFG component, and (2) the change due to $M F G$ 's quantity supply change. These two factors are then compared to examine the irrelative impact on the WSSR.

Recalling the definition of food self-sufficiency ratio, WSSR is defined as the magnitude of domestic production in relation to overall domestic utilization. In other words, WSSR is the fraction of the total domestic utilization times its own self-sufficiency ratio (which equals domestic production) over the total domestic utilization. In mathematical terms, WSSR - hereinafter denoted by $R$-is defined as follows:

$$
R=\frac{\sum_{i \in N} p_{i} w_{i}}{\sum_{i \in N} w_{i}}
$$

where,

\begin{tabular}{ccc}
\hline$p_{i}$ & $:$ & $M F G i ’ s$ weight-based self-sufficiency ratio, $i \in N ;$ \\
$w_{i}$ & $:$ & MFGi's quantity (weight) supply, $i \in N$, \\
\hline
\end{tabular}

The first derivative of (4) with respect to time shows that changes in $R$ consists of both changes in $p_{i}$ and $w_{i}$. In general terms, the annual change in Japan's food self-sufficiency ratio is the combination of a component change in the self-sufficiency ratios of the concerned $M F G$ and a component change in the quantity of those $M F G$ 's supply. Specifically, a small change in the value of $R$, denoted as $\Delta R$, can be decomposed into two components corresponding to the SSR change and the quantity change respectively, as follows:

$$
\frac{\mathrm{d} R}{\mathrm{~d} t}=\sum_{i \in N} \frac{\partial R}{\partial p_{i}} \frac{\mathrm{d} p_{i}}{\mathrm{~d} t}+\sum_{i \in N} \frac{\partial R}{\partial w_{i}} \frac{\mathrm{d} w_{i}}{\mathrm{~d} t}
$$

Denoting the above "annual" changes corresponding to the changes for $R, p_{i}$ and $w_{i}$ as $\Delta R, \Delta p_{i}$ and $\Delta w_{i}$, respectively, we can rewrite the expression in (5) as follows.

$$
\Delta R=\sum_{i \in N} \frac{\partial R}{\partial p_{i}} \Delta p_{i}+\sum_{i \in N} \frac{\partial R}{\partial w_{i}} \Delta w_{i}
$$

Let $W=\sum_{i \in N} w_{i}$ be the total supply for domestic utilization, then the right-hand-side (RHS) terms in (6) could be rewritten as:

$$
\begin{aligned}
& \frac{\partial R}{\partial p_{i}}=\frac{w_{i}}{W}, \quad i \in N \\
& \frac{\partial R}{\partial w_{i}}=\frac{1}{W}\left(p_{i}-\frac{\sum_{i \in N} p_{i} w_{i}}{W}\right)=\frac{\sum_{j \in N, j \neq i}\left(p_{i}-p_{j}\right) w_{j}}{W^{2}}=\frac{p_{i}-R}{W}, \quad i \in N \\
& \Delta p_{i}=p_{i}^{t}-p_{i}^{t-1} \text { and } \Delta w_{i}=w_{i}^{t}-w_{i}^{t-1}, i \in N
\end{aligned}
$$

Replacing (7) and (8) in (6) yields

$$
\Delta R=\sum_{i \in N}\left(\frac{w_{i}}{W}\right)\left(p_{i}^{t}-p_{i}^{t-1}\right)+\sum_{i \in N}\left(\frac{p_{i}-R}{W}\right)\left(w_{i}^{t}-w_{i}^{t-1}\right)
$$




$$
\Delta R=\Delta R_{p}+\Delta R_{w}
$$

Note that the left-hand-side (LHS) in (9) is the total annual change in Japan's food self-sufficiency ratio. The first term of the RHS in (9) is the factorial change in the major food groups' self-sufficiency ratios, and the second term is the factorial change of their supply quantities.

\subsection{Numerical Results for Factorial Component Changes}

The numerical results for the WSSR for each of the $20 M F G$, and the values for all the terms in (6) were computed through (9) using the 2010 FAO data for Japan's Food Balance Sheets from 1961 to 2011. The results are presented in the Table A in the Appendix and in Table 3 below.

Table 3. Numerical results for $W, R, \Delta R, \Delta R_{p}$ and $\Delta R_{w}$.

\begin{tabular}{|c|c|c|c|c|c|c|c|c|c|c|}
\hline & 1961 & 1962 & 1963 & 1964 & 1965 & 1966 & 1967 & 1968 & 1969 & 1970 \\
\hline $\mathbf{W}$ & 495.0 & 515.7 & 537.1 & 541.3 & 548.2 & 563.1 & 577.8 & 599.2 & 593.3 & 601.5 \\
\hline $\boldsymbol{R}$ & 86.4 & 84.8 & 82.2 & 79.9 & 80.0 & 77.5 & 77.7 & 77.2 & 74.7 & 72.3 \\
\hline$\Delta R$ & & -1.355 & -2.217 & -2.161 & 0.710 & -1.502 & -0.130 & -0.154 & -1.486 & -1.642 \\
\hline$\Delta \boldsymbol{R}_{p}$ & & -1.606 & -2.616 & -2.001 & 0.333 & -1.604 & -0.011 & -0.658 & -1.151 & -1.432 \\
\hline \multirow[t]{2}{*}{$\Delta \boldsymbol{R}_{w}$} & & 0.251 & 0.399 & -0.160 & 0.377 & 0.102 & -0.119 & 0.503 & -0.335 & -0.210 \\
\hline & 1971 & 1972 & 1973 & 1974 & 1975 & 1976 & 1977 & 1978 & 1979 & 1980 \\
\hline$W$ & 604 & 623.9 & 619.1 & 609.7 & 612.7 & 611.8 & 634 & 639.1 & 646.3 & 637.5 \\
\hline $\boldsymbol{R}$ & 71.2 & 70.7 & 68.8 & 67.9 & 68.6 & 66.2 & 66.0 & 65.7 & 64.9 & 63.8 \\
\hline$\Delta \boldsymbol{R}$ & -0.316 & -0.083 & -1.484 & -0.848 & 0.550 & -2.331 & 0.224 & 0.453 & -0.237 & -0.542 \\
\hline$\Delta R p$ & -0.864 & -0.434 & -1.412 & -0.683 & 0.186 & -1.976 & -0.467 & 0.298 & -0.256 & -0.220 \\
\hline \multirow[t]{2}{*}{$\Delta \boldsymbol{R}_{w}$} & 0.548 & 0.351 & -0.073 & -0.165 & 0.363 & -0.355 & 0.691 & 0.155 & 0.019 & -0.322 \\
\hline & 1981 & 1982 & 1983 & 1984 & 1985 & 1986 & 1987 & 1988 & 1989 & 1990 \\
\hline$W$ & 627.8 & 642.3 & 643.3 & 636 & 649.9 & 656.8 & 667.3 & 674.3 & 683.3 & 674.1 \\
\hline$R$ & 64.9 & 65.6 & 64.8 & 65.2 & 64.0 & 63.7 & 62.5 & 61.4 & 61.4 & 60.8 \\
\hline$\Delta \boldsymbol{R}$ & 0.753 & 0.686 & -0.544 & 0.068 & -1.089 & -0.018 & -0.665 & -1.690 & 0.001 & -0.431 \\
\hline$\Delta \boldsymbol{R}_{p}$ & 0.707 & 0.414 & -0.501 & 0.145 & -1.143 & -0.410 & -1.055 & -1.930 & 0.132 & -0.470 \\
\hline \multirow[t]{2}{*}{$\Delta \boldsymbol{R}_{w}$} & 0.046 & 0.272 & -0.043 & -0.077 & 0.054 & 0.391 & 0.390 & 0.240 & -0.131 & 0.039 \\
\hline & 1991 & 1992 & 1993 & 1994 & 1995 & 1996 & 1997 & 1998 & 1999 & 2000 \\
\hline$W$ & 670.4 & 678.9 & 669.5 & 677 & 679.6 & 677.5 & 670.6 & 652.1 & 658.9 & 655.2 \\
\hline $\boldsymbol{R}$ & 58.8 & 58.5 & 56.9 & 57.2 & 55.6 & 55.3 & 55.4 & 54.7 & 54.0 & 53.6 \\
\hline$\Delta R$ & -1.955 & -0.166 & -1.230 & -0.846 & -1.834 & -0.017 & 0.455 & -1.200 & -0.709 & -0.974 \\
\hline$\Delta \boldsymbol{R}_{p}$ & -1.921 & -0.475 & -1.076 & -1.120 & -1.847 & 0.133 & 0.566 & -0.784 & -0.640 & -0.736 \\
\hline \multirow[t]{2}{*}{$\Delta \boldsymbol{R}_{w}$} & -0.034 & 0.309 & -0.155 & 0.274 & 0.013 & -0.151 & -0.110 & -0.416 & -0.069 & -0.238 \\
\hline & 2001 & 2002 & 2003 & 2004 & 2005 & 2006 & 2007 & 2008 & 2009 & 2010 \\
\hline$W$ & 649.9 & 640.6 & 631.8 & 627.7 & 628.4 & 609.8 & 616.5 & 598.8 & 585.8 & 581 \\
\hline $\boldsymbol{R}$ & 53.1 & 52.5 & 52.2 & 52.1 & 52.2 & 51.7 & 52.8 & 53.5 & 52.7 & 51.4 \\
\hline$\Delta \boldsymbol{R}$ & -0.657 & -0.720 & -0.235 & -1.089 & -0.128 & -0.576 & 0.942 & 0.428 & -0.265 & -1.649 \\
\hline$\Delta \boldsymbol{R}_{p}$ & -0.263 & -0.155 & -0.101 & -0.924 & 0.066 & -0.513 & 1.085 & 0.388 & -0.082 & -1.282 \\
\hline \multirow[t]{2}{*}{$\Delta \boldsymbol{R}_{w}$} & -0.394 & -0.565 & -0.134 & -0.165 & -0.194 & -0.063 & -0.142 & 0.040 & -0.183 & -0.366 \\
\hline & 2011 & & & & & & & & & \\
\hline$W$ & 591.7 & & & & & & & & & \\
\hline $\boldsymbol{R}$ & 51.3 & & & & & & & & & \\
\hline$\Delta \boldsymbol{R}$ & -0.727 & & & & & & & & & \\
\hline$\Delta \boldsymbol{R}_{p}$ & -0.877 & & & & & & & & & \\
\hline$\Delta \boldsymbol{R}_{w}$ & 0.150 & & & & & & & & & \\
\hline
\end{tabular}


Using the breakdown in formula (6), we can map the relations between WSSR's annual factorial changes, $\Delta R_{p}$ and $\Delta R_{w}$, and the total changes $\Delta R$. Using the computed data, the graphs in Figure 2 show those relations and the 3-period moving average trend for $\Delta R$.

Figure 2 shows that a strong correlation between the factorial change in MFG's WSSR $\left(\Delta R_{p}\right)$ and the total change in WSSR $(\Delta R)$ does exist, but we cannot find a relation between the factorial change in MFG's quantity supply $\left(\Delta R_{w}\right)$ and $\Delta R$. The graphs show that $\Delta R_{w}$ fluctuated in a narrow band close to the origin 0.0 and registered mostly positive values except for the period after year 1995. On the other hand, $\Delta R_{p}$ and $\Delta R$ took on mostly negative values and moved in close tandem with each other in a much wider fluctuation, mainly below zero. Positive values and minor adjustments or changes in MFG's supply tend to stabilize and mitigate the total changes in WSSR. Nonetheless, changes in MFG's WSSR diminish that effect as sharp falls tend to cause a drastic fall in the total change in WSSR. The 3-year moving average trend line also shows that, on average, $\Delta R$ moved in a wide band far below zero in a way that reflected the broad negative fluctuation of $\Delta R_{p}$, and cancelling out the positive effect brought about by $\Delta R_{w}$. The moving average stays mostly below zero, implying and verifying the fact that WSSR declines most of the time.

This data analysis shows that the declining trend of WSSR is mainly due to the declining trend of the MFG's WSSR rather than due to the changes in MFG's quantity supply.

\subsection{Trend Analysis on the Factorial Change}

We analyze the time series trend of factorial component changes in order to investigate the change in the WSSR in more detail. We divide the whole time span of 1961-2011 into four sub-periods, trying to find the specific characteristic of the three elements concerned $\left(\Delta R, \Delta R_{p}\right.$ and $\left.\Delta R_{w}\right)$ in each of these four sub-periods, which we denote by I, II, III, and IV, respectively.

Sub-period I (1961-1976): This is the longest sub-period, characterized by large negative values for $\Delta R$ and $\Delta R_{p}$. During the sub-period the rise in the values for $\Delta R_{w}$ kept the values for $\Delta R$ from falling more than they did. This period corresponds to the time when many food-related policies, such as the rice diversion program, which started in 1970 to reduce the domestic rice production by $30 \%-40 \%$, thus policy changes were adopted in Japan. The period also saw the "westernization" of Japanese diets. Although agricultural production in this period performed satisfactorily, new demands created huge shortages in food items which were not produced domestically. The outcome was a sharp fall in the values of $\Delta R_{p}$ for many food items (i.e., $M F G$ ) which led to the sharp fall in the values of $\Delta R$ (i.e., WSSR). Major falls occurred in rice, grain and wheat in the "Cereals" MFG and in potatoes and sweet potatoes in the "Starchy Roots" $M F G$. On the other hand, weights of vegetables, fish, seafood, milk and fruits increased in a large scale, which made the values of $\Delta R_{w}$ rather stable.

Sub-period II (1977-1984): This is the shortest sub-period, lasting only eight years, where the fluctuations in $\Delta R$ and $\Delta R_{p}$ were within a narrow band. Again in this sub-period, the values for $\Delta R_{w}$ remained mostly highly and strongly positive. $\Delta R$ remained only slightly negative through this period, and for some years even rose into positive territory. This period came after a long period of decline in the WSSR that had begun to alarm Japanese in the early 1970s, following the Oil Crisis that rocked Japan's economy. A mild "return to local foodstuff" saw the WSSR rise somewhat. However, Japan's relatively open agricultural trade policy tended to offset the return, and the WSSR fluctuated during this time. Major contributors to the fluctuation were grain and wheat in the "Cereals" MFG. New impacts came from wine and alcoholic beverages in the "Alcoholic Beverages" MFG, the "Vegetables" MFG, and a range of foreign fruits from the "Fruits-Excluding Wine" MFG.

Sub-period III (1985-1996): During this period, Japan returned to the pattern that had been found for the first sub-period. It was characterized by negative values for $\Delta R$ and $\Delta R_{p}$ (though with slightly smaller values). The values for $\Delta R_{w}$ were positive from 1985-1989. Then they turned negative, which, together with $\Delta R_{p}$, amplified the negative values being registered for $\Delta R$. This period marks the beginning of Japan being the world's largest net food importer. High volumes of imports in wheat, grain in the "Cereals" $M F G$, in potatoes in "Starchy Roots", in wine and alcoholic beverages in "Alcoholic Beverages", in tomatoes, onions and other vegetables in "Vegetables", in apples, bananas, oranges, pineapples, grapes in "Fruits-Excluding Wine" contributed mostly to low negative values in $\Delta R_{p}$. The new commodities were marine fish and other seafood in the "Fish, Seafood" $M F G$, and bovine meat, mutton and goat meat in the "Meat" MFG.

Sub-period IV (1997-2005): This was a stable, but all negative period. The values for $\Delta R_{p}$ and $\Delta R_{w}$ were negative almost all time, thereby keeping those for $\Delta R$ in the negative zone. The moving average was quite 


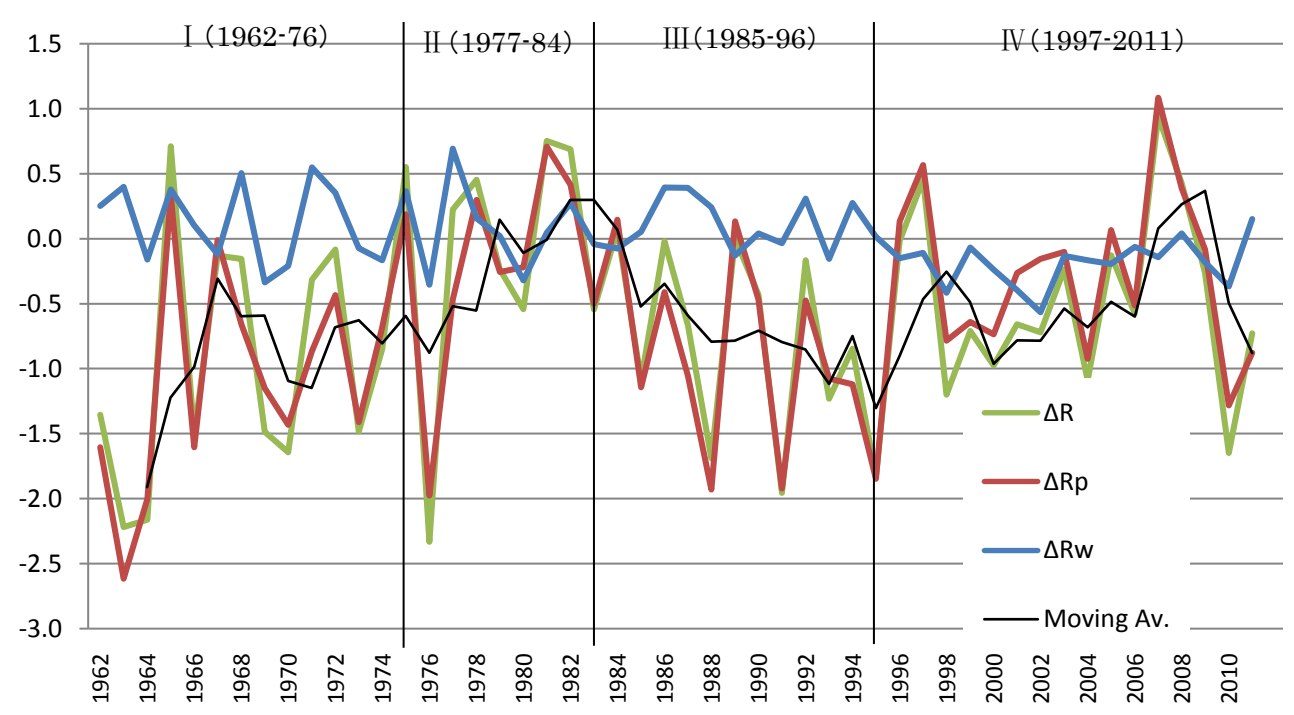

Figure 2. $\Delta R_{p}, \Delta R_{w}, \Delta R$ and its 3-year moving average of $\Delta R$.

smooth and the negative scale was not that as much as that of the former three sub-groups. Thus the "stabilized period" is explainable. After three periods of sharp declines and fluctuation, the values for $\Delta R_{p}$ and $\Delta R_{w}$ seem to "adapt" themselves to the new domestic demands and dietary habits. This results in a more stable set of slightly negative values for $\Delta R$. The commodities remain those noted above.

\section{Investigation on the Relation among Factorial Component Changes}

\subsection{Impact of Factorial Component Changes on the Total Change}

To analyze the impact of factorial component changes on the total change, the values for $\Delta R_{p}$ and $\Delta R_{w}$ are individually regressed against those for $\Delta R$. Figure 2 plots the two combinations $\left(\Delta R, \Delta R_{p}\right)$ and $\left(\Delta R, \Delta R_{w}\right)$ to represent the comparative relation between the two components and the total change. We note that, firstly, the values for the total change $\Delta R$ vary within an interval ranging from -3.0 to 1.0. Secondly, the values for the factorial component change $\Delta R_{p}$ range within the same interval $-3.0<\Delta R_{p}<1.0$. Thirdly, the values for the factorial component change $\Delta R_{w}$ range in a much narrower interval $-0.5<\Delta R_{w}<0.5$.

The graphs in Figure 3 show that the data points for the $\left(\Delta R, \Delta R_{p}\right)$ combinations, letting $\Delta R$ and $\Delta R_{p}$ expressed by $x$ and $y$, respectively, are best explained by the single variable linear regression model $y=0.874 x-$ 0.124 (with $R^{2}=0.897$ ). This means that the component change $\Delta R_{p}$ is generally explained by the total change $\Delta R$ with almost $90 \%$ goodness of fit. Moreover, only one-fifth (20\%) of the $\left(\Delta R, \Delta R_{p}\right)$ combinations, i.e., 9 out of 50 combinations, are located in the first coordinate while almost $70 \%$, i.e., 37 out of 50 combinations, are in the third coordinate, meaning the negative change in the values for $\Delta R$ is mostly attributed to the negative change in the values for $\Delta R_{p}$, not that of those for $\Delta R_{w}$. In other words, the declining trend of WSSR is attributed to the decline in the self-sufficiency ratios of the foodstuff themselves, not that of the change in the food supply quantity.

On the other hand, the graph does not show a satisfactory correlation for the $\left(\Delta R, \Delta R_{w}\right)$ combinations. These combinationsscatter along a narrow rectangle given by $-3.0<\Delta R<1.0$, and $-0.5<\Delta \mathrm{R}_{\mathrm{w}}<0.5$, meaning that the factorial component $\Delta R_{w}$ has not changed on a large scale in the past 45 years and has not contributed greatly to the total change $\Delta R$. We also note that data points in the first coordinate (i.e., positive values for both $\Delta R$ and $\Delta R_{w}$ ) stay close to the origin, implying not much change and impact on $\Delta R$. Positive changes in $\Delta R_{w}$ are mostly reflected in the increase in Calorie supply (kcal/capita/day) rather than in $\Delta R$ and WSSR as a whole.

\subsection{Relation between Factorial Components}

Table 4 presents the frequency of the values for $\Delta R_{p}$ and $\Delta R_{w}$ during the reference period. It shows how they are distributed, over 51 years as a whole (50 years of changes), and in each of the above-mentioned four sub-periods in particular. It can be seen from the table that the number of years when the values for $\Delta R_{w}$ are nonnegative and that when the values for $\Delta R_{w}$ are negative are equal as 23 and 27, respectively, thus they are not so different. 


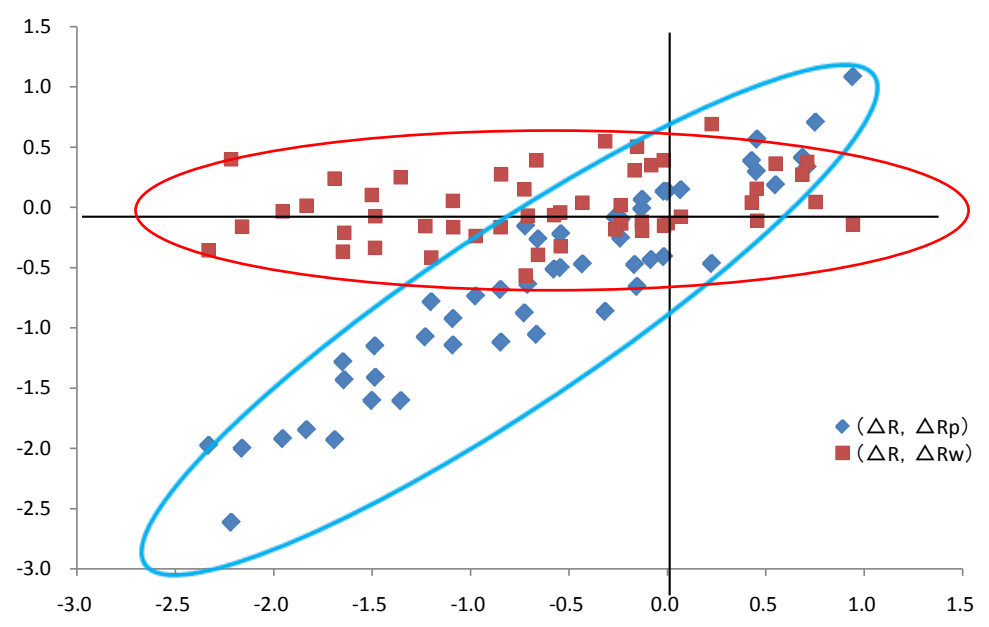

Figure 3. Plots of $\left(\Delta R, \Delta R_{p}\right)$ and $\left(\Delta R, \Delta R_{w}\right)$.

Table 4. $\Delta R_{p}$ and $\Delta R_{w}$ frequency.

\begin{tabular}{|c|c|c|c|c|c|c|c|}
\hline \multirow[b]{2}{*}{ Sub-period } & \multicolumn{4}{|c|}{$\Delta R_{p}$} & \multicolumn{3}{|c|}{$\Delta R_{w}$} \\
\hline & $\Delta R_{p}<-2$ & $-2<\Delta R_{p}<-1$ & $-1<\Delta R_{p}<0$ & $0<\Delta R_{p}$ & $\Delta R_{w}<-1$ & $-1<\Delta R_{w}<0$ & $\begin{array}{l}0< \\
\triangle R_{w}\end{array}$ \\
\hline $\begin{array}{c}\text { I } \\
(1962-1976)\end{array}$ & 2 & 6 & 5 & 2 & 0 & 7 & 8 \\
\hline $\begin{array}{c}\text { II } \\
(1977-1984)\end{array}$ & 0 & 0 & 4 & 4 & 0 & 3 & 5 \\
\hline $\begin{array}{c}\text { III } \\
(1985-1996)\end{array}$ & 0 & 7 & 3 & 2 & 0 & 4 & 8 \\
\hline $\begin{array}{c}\text { IV } \\
(1997-2011)\end{array}$ & 0 & 1 & 10 & 4 & 0 & 13 & 2 \\
\hline Total & 2 & 14 & 22 & 12 & 0 & 27 & 23 \\
\hline
\end{tabular}

On the other hand, regarding the values of $\Delta R_{p}$, they are positive only 12 years among 50 years while other 38 years show negative values.

In the sub-period I only 2 years out of 15 are in the $1^{\text {st }}$ coordinate, i.e., $\Delta R_{p}$ and $\Delta R_{w}$ are both positive while other 6 years are in the $2^{\text {nd }}$ coordinate, i.e., $\Delta R_{p}$ negative and $\Delta R_{w}$ positive, and 7 years are in the $3^{\text {rd }}$ coordinate, i.e., $\Delta R_{p}$ and $\Delta R_{w}$ are both negative. In the sub-period II 3 years are distributed in the $1^{\text {st }}$ coordinate and 1 year is in the $4^{\text {th }}$ coordinate, i.e., $\Delta R_{p}$ positive and $\Delta R_{w}$ negative while 2 years are in the $2^{\text {nd }}$ and $3^{\text {rd }}$ coordinates, respectively. In the sub-period III 2 years out of 12 in total are in the $2^{\text {nd }}$ coordinate while remaining 8 years are in the $2^{\text {nd }}$ coordinate and 2 years are in the $3^{\text {rd }}$ coordinate. In the sub-period IV only 1 year out of 15 in total is in the $1^{\text {st }}$ coordinate while remaining 10 years are in the $3^{\text {rd }}$ coordinate and only 1 year and 2 years are exceptionally in the $2^{\text {nd }}$ and $4^{\text {th }}$ coordinates, respectively.

Thus, we find that most sub-periods, excluding II, show dominatingly negative $\Delta R_{p}$ no matter how $\Delta R_{w}$ are valued. This trend in the sub-period I is due to the decrease (increase) in supply (import) in majorly grains. In the sub-section III similar trend comes from decreasing supply of rice, vegetables, fruits, meat and fish. Sub-period IV shows the decreasing trend of major food items excluding meat corresponds to the negative $\Delta R_{w}$. Subperiod II shows that both $\Delta R_{p}$ and $\Delta R_{w}$ are close to zero.

Figure 4 graphs the time series changes in the four sub-periods, and for the 1962-2011 period as a whole, relative to a center point. We find that $\Delta R_{p}$ and $\Delta R_{w}$ follow two different paths unrelated each other. In all four sub-periods, $\Delta R_{w}$ tended to be stably staying around the circular line corresponding to the value zero while $\Delta R_{p}$ unsteadily scattered along the scale and mostly staying in the area corresponding to "negative" points. We find that the graphs reiterate $\Delta R_{p}$ 's tendency of being mostly negative for sub-periods I and III while it is mostly close to $\Delta R_{w}$ 's for sub-periods II and IV.

We also note that the values of the center points are all different for these figures while the scale for each sub-period is also different. This means $\Delta R_{p}$ and $\Delta R_{w}$ vary in each sub-period as we see the different shapes of 

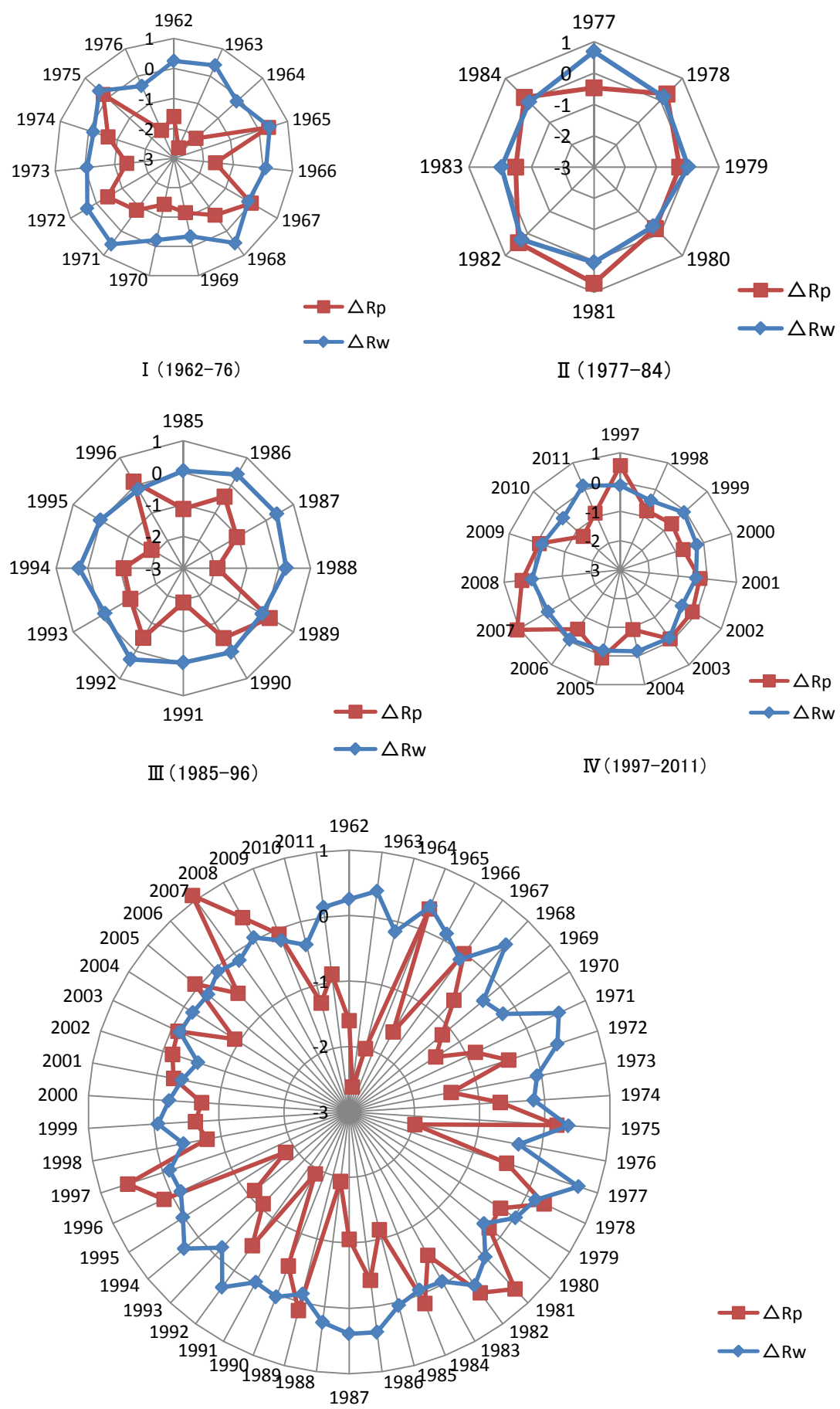

Figure 4. $\Delta R_{p}$ and $\Delta R_{w}$ in 4 sub-periods and all.

the graphs. Moreover, we learn that there were but 8 years (out of 50, or 16\%) in the reference period where $\Delta R_{p}$ and $\Delta R_{w}$ took on positive values, and stayed close to each other. Those were in $1965,1975,1978,1981,1982$, and 2008. It explains why the total change $\Delta R$ were mostly negative, and WSSR declined during the 1961-2011 period.

\subsection{Impact of $M F G$ on the Factorial Component Changes}

Of all $20 M F G$ concerned, the impacts they have on $\Delta R_{p}$ and $\Delta R_{w}$ (and, therefore, on $\Delta R$ ) are quite different. We 
compute minimum, median and maximum of $\Delta R_{p}$ and $\Delta R_{w}$ for all $20 M F G$ in the reference period to observe such impacts. Table 5 presents these minimums, medians and maximum, and Table 6 lists the top 10 MFG with the greatest impacts on $\Delta R_{p}$ and $\Delta R_{w}$, respectively. The ranking is based on (1) the scale of the impact with respect to the median, and (2) the nature of MFG's fluctuation pattern. These Table 5 and Table 6 are obtained from calculating numerical results given in Table $\mathbf{A}$ in the Appendix.

From Table 5 and Table 6 we find that regarding the median of $\Delta R_{w}$, changes of supply for "Cereals", "Alcoholic Beverages", and "Fish, Seafood" give rather positive impacts while only "Starchy Roots" gives rather negative impact. Negative impact due to "Starchy Roots", even though small, may result from the fact that they are transformed into some other consuming foods rather than directly consumed in the market. Also regarding the median of $\Delta R_{p}$, only "Sugar \& Sweeteners" brings small positive impact while other "Cereals", "Fruits", and "Fish, Seafood" bring large negative impacts. These large negative impacts may result from the fact that we have been importing these foods such as "Cereals", "Fruits", and "Fish, Seafood" constantly and largely as major foods in Japan.

As shown in Table 5 and Table 6, we see that maximum values with respect to $\Delta R_{p}$ are very high for "Cereals", "Starchy Roots", "Sugar \& Sweeteners", "Alcoholic Beverages”, and "Fish, Seafood”, and their minimum values are generally very small, which implies that these foods including "Vegetables" and "Meat" have both large positive and large negative impacts on our $\Delta R$. The "Cereals" $M F G$ has the second largest and highly important impact on both $\Delta R_{p}$ and $\Delta R_{w}$. The "Fish, Seafood" $M F G$ has more impact on $\Delta R_{p}$ and less on $\Delta R_{w}$ while "Meat" and "Vegetable Oils" have almost the same importance in affecting $\Delta R_{p}$ and $\Delta R_{w}$. The $M F G$ "Cereals”, "Starchy Roots”, "Fish, Seafood”, "Meat”, "Vegetables”, "Vegetable Oils”, "Milk”, "Alcoholic Beverages" are presented in both columns, implying their importance in Japanese diets. The missing MFG in the list (“Sugarcrops”, “Treenuts”, “Oilcrops”, “Spices”, “Offals”, “Animal Fats”, “Aquatic Products, Other”) reveals that food policy-making process can target these MFG without much impact on WSSR. On the other hand, policy makers should be careful when targeting MFG in the Top 10 list in order to avoid an unwanted impact on $\Delta R_{p}$ and/or $\Delta R_{w}$, and therefore on $\Delta R$ and WSSR.

Table 5. Impact of $M F G$ on $\Delta R_{p}$ and $\Delta R_{w}$.

\begin{tabular}{|c|c|c|c|c|c|c|}
\hline \multirow{2}{*}{$M F G$} & \multicolumn{3}{|c|}{$\Delta R_{p}$} & \multicolumn{3}{|c|}{$\Delta R_{w}$} \\
\hline & Min & Median & Max & Min & Median & Max \\
\hline Cereals-Excluding Beer & -1.809 & -0.118 & 0.696 & -0.233 & 0.040 & 0.312 \\
\hline Starchy Roots & -0.844 & -0.030 & 0.566 & -0.232 & -0.019 & 0.136 \\
\hline Sugar Crops & 0.000 & 0.000 & 0.000 & 0.000 & 0.000 & 0.000 \\
\hline Sugar \& Sweeteners & -0.328 & 0.021 & 0.610 & -0.357 & 0.000 & 0.238 \\
\hline Pulses & -0.140 & -0.010 & 0.133 & -0.018 & 0.000 & 0.024 \\
\hline Tree Nuts & -0.020 & -0.003 & 0.012 & -0.014 & 0.000 & 0.013 \\
\hline Oil Crops & -0.123 & -0.004 & 0.016 & -0.059 & 0.000 & 0.058 \\
\hline Vegetable Oils & -0.118 & -0.010 & 0.056 & -0.017 & 0.008 & 0.036 \\
\hline Vegetables & -0.454 & -0.075 & 0.291 & -0.266 & -0.023 & 0.375 \\
\hline Fruits-Excluding Wine & -0.414 & -0.115 & 0.323 & -0.173 & 0.004 & 0.186 \\
\hline Stimulants & -0.036 & -0.004 & 0.014 & -0.037 & -0.006 & 0.040 \\
\hline Spices & -0.012 & 0.000 & 0.030 & -0.022 & 0.000 & 0.020 \\
\hline Alcoholic Beverages & -0.549 & -0.010 & 0.535 & -0.330 & 0.051 & 0.269 \\
\hline Meat & -0.438 & -0.060 & 0.338 & -0.010 & 0.012 & 0.060 \\
\hline Offals & -0.022 & -0.002 & 0.059 & -0.033 & 0.002 & 0.013 \\
\hline Animal Fats & -0.079 & -0.002 & 0.081 & -0.013 & 0.000 & 0.018 \\
\hline Eggs & -0.040 & -0.003 & 0.034 & -0.047 & 0.006 & 0.071 \\
\hline Milk-Excluding Butter & -0.793 & 0.009 & 0.561 & -0.124 & 0.000 & 0.109 \\
\hline Fish, Seafood & -0.794 & -0.183 & 0.613 & -0.140 & 0.012 & 0.178 \\
\hline Aquatic Products, Other & -0.062 & -0.002 & 0.065 & -0.030 & 0.000 & 0.016 \\
\hline
\end{tabular}


Table 6. Top $10 M F G$ affecting $\Delta R_{p}$ and $\Delta R_{w}$.

\begin{tabular}{lll}
\hline Rank & Impact on $\Delta R_{p}$ & Impact on $\Delta R_{w}$ \\
\hline $\mathbf{1}$ & Fish, Seafood & Alcoholic Beverages \\
$\mathbf{2}$ & Cereals-Excluding Beer & Cereals-Excluding Beer \\
$\mathbf{3}$ & Fruits-Excluding Wine & Vegetables \\
$\mathbf{4}$ & Vegetables & Starchy Roots \\
$\mathbf{5}$ & Meat & Meat \\
$\mathbf{6}$ & Starchy Roots & Milk-Excluding Butter \\
$\mathbf{7}$ & Sugar \& Sweeteners & Fish, Seafood \\
$\mathbf{8}$ & Vegetable Oils & Vegetable Oils \\
$\mathbf{9}$ & Milk-Excluding Butter & Stimulants \\
$\mathbf{1 0}$ & Alcoholic Beverages & Eggs \\
\hline
\end{tabular}

\section{Summary and Conclusions}

It is inarguable that food self-sufficiency has become a very serious policy issue in Japan. Local scholars and bureaucrats believe the country's Food SSR has been as low as $40 \%$ in the recent trend from 2005 until now on a calorie basis. The results in this paper show a higher value, 53\%, on a weight basis. Yet, it is still low, compared to that of $87 \%$ in 1961 . It is a drop of nearly 34 percentage points in 50 years. This situation puts a pressure on the country's agriculture sector and leaves national food security and national safety vulnerable.

By breaking $\Delta R$ into two major factorial component changes, $\Delta R_{p}$ and $\Delta R_{w}$, we were able to analyze and find that it was the change in the major food group's self-sufficiency ratio, $\Delta R_{p}$, that drove the change in $\Delta R$, not that of the change in the major food group's quantity supply, $\Delta R_{w}$.

The trend analysis concludes that $\Delta R_{p}$ and $\Delta R_{w}$, and that $\Delta R_{p}$ have a stronger and a greater impact on $\Delta R$ while there is no explicit relation between them. Thus we concluded that the decline of $\Delta R$ was mostly due to the decline in major food group's self-sufficiency ratio $\left(\Delta R_{p}\right)$. We also found that the values for $\Delta R_{p}$ and those for $\Delta R$ can be well explained by a linear equation, with an almost $90 \%$ goodness of fit. On the other hand, we could not find any satisfactory expression to explain the values of $\Delta R_{w}$ and those for $\Delta R$.

We also divided the reference period into four sub-periods to investigate the characteristics of the changes and to explain WSSR's overall declining trend. We noted the differences in the characteristics of each sub-per- iod, and found the commodities that contributed to such characteristics.

We also computed and listed the top $10 M F G$ that had the greatest impacts on both $\Delta R_{p}$ and $\Delta R_{w}$ in particular and $\Delta R$ as a whole. Among them, the "Cereals" $M F G$ proved to have had the major and most highly important impact on both $\Delta R_{p}$ and $\Delta R_{w}$. The $M F G$ "Starchy Roots", "Fish, Seafood", "Meat", "Vegetables", "Vegetable Oils", "Milk", "Alcoholic Beverages" all displayed their importance in the Japanese diets. These are the MFG that the policy-making process needs to pay more attention to in order to avoid a negative impact on $\Delta R_{p}$ and/or $\Delta R_{w}$, and thus on $\Delta R$ and WSSR.

By studying $\Delta R_{p}$ and $\Delta R_{w}$-the endogenous factors of WSSR, the paper partly fills the gap in the literature on Japan's food problems. The findings in this paper lead to many suggestions and implications for both policy makers and food researchers. From both the research and policy-making points of view, one obvious question, among others, would be to what extent WSSR can be recovered. What would be the maximum sustainable WSSR? In an attempt to find the answer to such questions, a study on food network flow programming is conducted. The optimal results from such optimization model would be significant for further investigation of food security in Japan.

\section{References}

[1] Ogura, T. (1976) Implication of Japan’s Declining Food Self-Sufficiency Ratio. The Development Economics, 14, 419448.

[2] Higuchi, T. (1991) Japanese Dietary Habits and Food Consumption. Committee for the Japanese Agriculture Session, XXI IAAE Conference, Agriculture and Agricultural Policy in Japan, University of Tokyo Press, Tokyo, 87-104. 
[3] Saeki, N. (1991) Development of Trade in Agricultural Products and Border Adjustment in Agriculture. Committee for the Japanese Agriculture Session, XXI IAAE Conference, Agriculture and Agricultural Policy in Japan, University of Tokyo Press, Tokyo, 121-142.

[4] Kako, T. (2009) Sharp Decline in the Food Self-Sufficiency Ratio in Japan and Its Future Prospects. Contributed Paper Prepared for Presentation at the International Association of Agricultural Economists Conference, Beijing, 16-22 August 2009.

http://ageconsearch.umn.edu/bitstream/51570/2/kako\%20Sharp\%20decline\%20in\%20food\%20self-sufficiency1.pdf

[5] Tanaka, T. and Hosoe, N. (2008) Productivity Shocks and National Food Security for Japan. RIETI Discussion Paper Series 09-E-004.

[6] Mashimo, T. (2008) To What Level Could Japan's Food Self-Sufficiency Recover? Paper Presented at the World Foodless Day in Tokyo. http://www.nishoren.org/en/?p=287

[7] Oyama, T. and Yoshii, K. (2006) Evaluation and Systematization of Policy for the Ministry of Agriculture, Forestry and Fisheries: Current Situation and Problems. In: Oyama, T., Ed., Theory and Practice for Public Policy Evaluation, Gendaitosho, Sagamihara, 281-295.

[8] Trung, N.H., Yoshii, K. and Oyama, T. (2009) Quantitative Data Analyses for the Recent Change of the Japanese Food Self-Sufficiency Ratios. The 8th International Symposium on Operations Research and Its Application (ISORA), Zhangjiajie, 20-22 September 2009, 372-386.

[9] Hayami, Y. and Godo, Y. (1997) Economics and Politics of Rice Policy in Japan: A Perspective on the Uruguay round. In: Ito, T. and Kruger, A.O., Eds., Regionalism versus Multilateral Trade Arrangements, University of Chicago Press, Chicago, 371-399.

[10] Hayami, Y. (2000) Food Security: Fallacy or Reality? In: Chern, S.W., Carter, C.A. and Shei, S., Eds., Food Security in Asia: Edward Elgar, 11-17.

[11] Japan Ministry of Agriculture, Forestry and Fisheries (2000-2008) Various Reports and Papers. 
Appendix

Table A. 20 Major food groups’ self-sufficiency ratios, Japan 1961-2011.

\begin{tabular}{|c|c|c|c|c|c|c|c|c|c|c|}
\hline & 1961 & 1962 & 1963 & 1964 & 1965 & 1966 & 1967 & 1968 & 1969 & 1970 \\
\hline $\begin{array}{c}\text { SSR Cereals- } \\
\text { Excluding Beer + }\end{array}$ & 70.2 & 67.5 & 60.3 & 55.6 & 55.0 & 50.6 & 53.5 & 52.1 & 46.1 & 39.0 \\
\hline SSR Starchy Roots + & 99.4 & 97.1 & 101.7 & 99.2 & 99.4 & 99.0 & 97.1 & 97.2 & 97.3 & 97.0 \\
\hline SSR Sugarcrops + & 100.0 & 100.0 & 100.0 & 100.0 & 100.0 & 100.0 & 100.0 & 100.0 & 100.0 & 100.0 \\
\hline $\begin{array}{l}\text { SSR Sugar \& } \\
\text { Sweeteners + }\end{array}$ & 27.7 & 30.6 & 31.2 & 38.8 & 37.0 & 32.8 & 31.9 & 28.5 & 25.7 & 23.5 \\
\hline SSR Pulses + & 84.2 & 66.1 & 65.0 & 46.7 & 63.3 & 50.6 & 67.7 & 59.4 & 51.1 & 67.1 \\
\hline SSR Treenuts + & 84.8 & 75.7 & 70.6 & 67.4 & 60.5 & 58.6 & 62.5 & 64.0 & 68.1 & 62.3 \\
\hline SSR Oilcrops + & 28.8 & 24.8 & -- & 15.0 & 13.9 & 10.6 & 9.3 & 7.9 & 6.4 & 5.1 \\
\hline SSR Vegetable Oils + & 100.8 & 98.2 & 95.9 & 95.2 & 97.9 & 97.9 & 96.9 & 96.0 & 94.7 & 96.7 \\
\hline SSR Vegetables + & 100.0 & 100.2 & 99.8 & 99.7 & 99.8 & 99.7 & 99.5 & 99.4 & 99.7 & 99.3 \\
\hline $\begin{array}{l}\text { SSR Fruits-Excluding } \\
\text { Wine }+\end{array}$ & 101.1 & 99.1 & 94.4 & 92.7 & 92.9 & 91.7 & 90.9 & 89.7 & 87.0 & 84.5 \\
\hline SSR Stimulants + & 73.2 & 65.5 & 57.0 & 56.8 & 56.1 & 47.4 & 48.0 & 45.9 & 43.5 & 40.8 \\
\hline SSR Spices + & 83.3 & 150.0 & 85.7 & 71.4 & 83.3 & 42.9 & 28.6 & 25.0 & 28.6 & 6.3 \\
\hline $\begin{array}{l}\text { SSR Alcoholic } \\
\text { Beverages + }\end{array}$ & 100.1 & 100.1 & 100.1 & 100.1 & 100.0 & 100.1 & 100.1 & 100.1 & 100.0 & 99.9 \\
\hline SSR Meat + & 94.8 & 95.6 & 91.4 & 91.1 & 93.7 & 88.0 & 88.9 & 87.5 & 84.8 & 88.4 \\
\hline SSR Offals + & 100.0 & 100.0 & 98.6 & 97.6 & 98.9 & 99.0 & 99.1 & 96.4 & 96.8 & 98.0 \\
\hline SSR Animal Fats + & 69.1 & 82.4 & 78.0 & 65.2 & 62.4 & 52.4 & 53.1 & 52.5 & 52.6 & 60.1 \\
\hline SSR Eggs + & 100.8 & 100.6 & 100.2 & 100.1 & 99.9 & 99.7 & 99.2 & 98.3 & 98.3 & 97.9 \\
\hline $\begin{array}{l}\text { SSR Milk-Excluding } \\
\text { Butter }+\end{array}$ & 85.5 & 82.1 & 78.1 & 77.4 & 80.5 & 79.5 & 74.0 & 80.2 & 83.2 & 84.8 \\
\hline SSR Fish, Seafood + & 108.1 & 106.0 & 101.2 & 96.3 & 97.7 & 99.7 & 99.5 & 94.9 & 98.7 & 100.2 \\
\hline \multirow[t]{2}{*}{$\begin{array}{l}\text { SSR Aquatic Products, } \\
\text { Other + }\end{array}$} & 88.7 & 90.2 & 88.6 & 84.8 & 86.0 & 77.8 & 84.4 & 85.7 & 82.2 & 82.0 \\
\hline & 1971 & 1972 & 1973 & 1974 & 1975 & 1976 & 1977 & 1978 & 1979 & 1980 \\
\hline $\begin{array}{l}\text { SSR Cereals-- } \\
\text { Excluding Beer + }\end{array}$ & 34.1 & 33.2 & 31.1 & 31.3 & 33.2 & 28.6 & 29.6 & 28.6 & 26.8 & 22.1 \\
\hline SSR Starchy Roots + & 96.6 & 103.0 & 96.6 & 88.5 & 84.3 & 93.1 & 92.0 & 90.7 & 92.3 & 92.4 \\
\hline SSR Sugarcrops + & 100.0 & 100.0 & 100.0 & 100.0 & 100.0 & 100.0 & 100.0 & 100.0 & 100.0 & 100.0 \\
\hline $\begin{array}{l}\text { SSR Sugar \& } \\
\text { Sweeteners + }\end{array}$ & 22.0 & 22.9 & 25.5 & 18.9 & 21.0 & 23.3 & 23.2 & 35.3 & 36.3 & 43.9 \\
\hline SSR Pulses + & 44.7 & 73.3 & 67.0 & 60.7 & 47.7 & 49.5 & 58.5 & 52.2 & 45.6 & 30.6 \\
\hline SSR Treenuts + & 56.8 & 57.7 & 53.8 & 60.2 & 53.1 & 42.1 & 47.2 & 46.9 & 50.4 & 43.1 \\
\hline SSR Oilcrops + & 4.6 & 4.3 & 3.8 & 4.4 & 4.0 & 3.5 & 3.4 & 4.5 & 4.5 & 4.1 \\
\hline SSR Vegetable Oils + & 100.1 & 93.8 & 87.2 & 84.2 & 85.4 & 82.1 & 84.4 & 84.8 & 84.1 & 85.6 \\
\hline SSR Vegetables + & 99.0 & 98.8 & 98.3 & 97.9 & 98.0 & 97.3 & 97.4 & 96.6 & 96.3 & 96.0 \\
\hline $\begin{array}{l}\text { SSR Fruits-Excluding } \\
\text { Wine }+\end{array}$ & 83.3 & 82.0 & 83.7 & 84.0 & 83.8 & 82.3 & 83.0 & 80.7 & 82.2 & 81.9 \\
\hline SSR Stimulants + & 38.3 & 34.7 & 35.2 & 35.1 & 36.1 & 33.4 & 32.3 & 34.2 & 27.0 & 27.6 \\
\hline SSR Spices + & 0.0 & 0.0 & 0.0 & 0.0 & 0.0 & 0.0 & 0.0 & 0.0 & 0.0 & 0.0 \\
\hline $\begin{array}{l}\text { SSR Alcoholic } \\
\text { Beverages + }\end{array}$ & 99.4 & 99.3 & 99.2 & 98.4 & 99.0 & 96.3 & 96.4 & 96.0 & 95.5 & 94.9 \\
\hline SSR Meat + & 86.5 & 83.1 & 78.4 & 87.4 & 83.9 & 80.1 & 82.4 & 82.9 & 82.5 & 85.3 \\
\hline SSR Offals + & 97.6 & 96.8 & 94.4 & 97.2 & 90.6 & 84.7 & 84.0 & 81.5 & 83.4 & 83.5 \\
\hline SSR Animal Fats + & 61.4 & 58.8 & 60.8 & 77.8 & 76.8 & 69.4 & 84.4 & 84.0 & 92.4 & 91.0 \\
\hline SSR Eggs + & 98.1 & 98.1 & 97.8 & 98.1 & 97.9 & 97.7 & 97.6 & 98.1 & 98.1 & 98.4 \\
\hline $\begin{array}{l}\text { SSR Milk - Excluding } \\
\text { Butter + }\end{array}$ & 86.9 & 86.1 & 84.9 & 81.0 & 82.4 & 74.0 & 72.8 & 71.3 & 72.8 & 74.9 \\
\hline SSR Fish, Seafood + & 104.7 & 101.4 & 97.8 & 98.8 & 98.8 & 98.9 & 91.2 & 95.7 & 93.6 & 93.8 \\
\hline $\begin{array}{c}\text { SSR Aquatic Products, } \\
\text { Other + }\end{array}$ & 80.4 & 77.0 & 73.3 & 77.5 & 81.1 & 66.6 & 65.3 & 71.5 & 65.6 & 82.8 \\
\hline
\end{tabular}




\begin{tabular}{|c|c|c|c|c|c|c|c|c|c|c|}
\hline & 1981 & 1982 & 1983 & 1984 & 1985 & 1986 & 1987 & 1988 & 1989 & 1990 \\
\hline SSR Cereals-Excluding Beer + & 23.6 & 23.8 & 23.6 & 25.8 & 25.5 & 24.8 & 22.5 & 22.1 & 22.6 & 22.8 \\
\hline SSR Starchy Roots + & 91.7 & 92.1 & 94.1 & 89.8 & 75.2 & 84.0 & 89.5 & 80.3 & 75.2 & 77.8 \\
\hline SSR Sugarcrops + & 100.0 & 100.0 & 100.0 & 100.0 & 100.0 & 100.0 & 100.0 & 100.0 & 100.0 & 100.0 \\
\hline SSR Sugar \& Sweeteners + & 53.0 & 49.8 & 48.6 & 52.4 & 51.3 & 51.4 & 50.3 & 51.2 & 51.7 & 51.3 \\
\hline SSR Pulses + & 31.5 & 51.8 & 33.0 & 59.7 & 47.2 & 40.7 & 42.4 & 41.1 & 43.4 & 48.6 \\
\hline SSR Treenuts + & 51.3 & 44.8 & 42.5 & 40.3 & 37.8 & 32.3 & 32.4 & 25.4 & 25.2 & 25.8 \\
\hline SSR Oilcrops + & 4.8 & 4.5 & 4.5 & 4.4 & 3.9 & 4.2 & 4.7 & 4.3 & 4.3 & 3.5 \\
\hline SSR Vegetable Oils + & 81.7 & 81.6 & 82.7 & 84.3 & 83.8 & 83.2 & 81.4 & 79.8 & 77.7 & 76.7 \\
\hline SSR Vegetables + & 95.4 & 96.3 & 95.7 & 94.4 & 95.1 & 94.5 & 93.9 & 91.5 & 91.8 & 91.7 \\
\hline SSR Fruits-Excluding Wine + & 80.2 & 80.7 & 82.4 & 77.8 & 78.8 & 75.5 & 75.8 & 72.6 & 70.5 & 68.8 \\
\hline SSR Stimulants + & 26.1 & 24.2 & 24.0 & 20.7 & 20.4 & 18.5 & 17.3 & 15.8 & 15.4 & 15.0 \\
\hline SSR Spices + & 0.0 & 0.0 & 0.0 & 0.0 & 0.0 & 0.0 & 0.0 & 0.0 & 0.0 & 25.0 \\
\hline SSR Alcoholic Beverages + & 95.2 & 95.7 & 95.0 & 94.3 & 94.8 & 95.1 & 94.5 & 93.5 & 93.1 & 93.2 \\
\hline SSR Meat + & 82.6 & 84.1 & 83.6 & 83.1 & 83.8 & 81.8 & 79.4 & 76.5 & 74.0 & 73.2 \\
\hline SSR Offals + & 80.8 & 81.9 & 81.6 & 80.4 & 78.4 & 75.5 & 75.4 & 72.7 & 72.9 & 73.2 \\
\hline SSR Animal Fats + & 99.3 & 104.7 & 110.9 & 121.1 & 113.6 & 110.3 & 101.5 & 122.5 & 101.7 & 106.0 \\
\hline SSR Eggs + & 98.3 & 98.6 & 98.9 & 99.1 & 99.0 & 98.4 & 99.1 & 99.0 & 98.9 & 98.8 \\
\hline SSR Milk-Excluding Butter + & 78.1 & 76.5 & 77.4 & 77.6 & 76.6 & 78.2 & 74.4 & 73.6 & 78.4 & 80.4 \\
\hline SSR Fish, Seafood + & 94.6 & 97.2 & 92.4 & 95.1 & 92.9 & 88.8 & 87.1 & 83.7 & 85.3 & 78.2 \\
\hline \multirow[t]{2}{*}{ SSR Aquatic Products, Other + } & 90.1 & 90.0 & 88.9 & 90.6 & 90.0 & 90.4 & 88.8 & 87.9 & 87.2 & 93.6 \\
\hline & 1991 & 1992 & 1993 & 1994 & 1995 & 1996 & 1997 & 1998 & 1999 & 2000 \\
\hline SSR Cereals-Excluding Beer + & 20.3 & 22.1 & 20.3 & 24.4 & 22.3 & 21.7 & 21.0 & 19.2 & 19.9 & 21.2 \\
\hline SSR Starchy Roots + & 77.9 & 76.9 & 75.4 & 78.9 & 82.2 & 79.3 & 81.5 & 80.0 & 78.1 & 76.6 \\
\hline SSR Sugarcrops + & 100.0 & 100.0 & 100.0 & 100.0 & 100.0 & 100.0 & 100.0 & 100.0 & 100.0 & 100.0 \\
\hline SSR Sugar \& Sweeteners + & 53.9 & 50.8 & 52.3 & 51.3 & 54.7 & 50.6 & 54.0 & 55.2 & 54.1 & 54.0 \\
\hline SSR Pulses + & 43.7 & 32.6 & 22.8 & 36.5 & 50.0 & 37.5 & 38.4 & 37.9 & 36.9 & 38.0 \\
\hline SSR Treenuts + & 19.9 & 20.6 & 15.8 & 19.6 & 18.2 & 17.2 & 19.0 & 15.8 & 18.0 & 13.5 \\
\hline SSR Oilcrops + & 3.3 & 3.1 & 1.7 & 1.9 & 2.2 & 2.6 & 2.1 & 2.3 & 2.6 & 3.2 \\
\hline SSR Vegetable Oils + & 75.5 & 75.0 & 74.3 & 73.7 & 73.1 & 73.8 & 72.8 & 73.7 & 76.0 & 75.7 \\
\hline SSR Vegetables + & 90.5 & 90.2 & 88.5 & 86.0 & 85.1 & 85.4 & 85.5 & 83.3 & 81.9 & 81.5 \\
\hline SSR Fruits-Excluding Wine + & 65.2 & 65.8 & 62.0 & 57.2 & 55.6 & 54.5 & 58.6 & 55.8 & 55.2 & 51.1 \\
\hline SSR Stimulants + & 14.1 & 15.1 & 14.9 & 13.3 & 13.8 & 13.0 & 13.5 & 12.9 & 12.8 & 11.6 \\
\hline SSR Spices + & 22.3 & 27.3 & 26.4 & 24.1 & 17.9 & 22.0 & 19.9 & 19.6 & 16.1 & 13.7 \\
\hline SSR Alcoholic Beverages + & 93.4 & 93.6 & 93.3 & 90.9 & 90.5 & 91.6 & 91.1 & 89.8 & 91.5 & 90.1 \\
\hline SSR Meat + & 71.0 & 67.9 & 66.3 & 63.3 & 56.5 & 54.3 & 56.8 & 56.2 & 53.8 & 51.6 \\
\hline SSR Offals + & 70.9 & 69.0 & 71.9 & 70.8 & 67.1 & 66.5 & 68.7 & 67.8 & 67.5 & 65.4 \\
\hline SSR Animal Fats + & 92.3 & 84.8 & 83.9 & 79.6 & 67.7 & 63.2 & 66.5 & 75.5 & 74.8 & 69.6 \\
\hline SSR Eggs + & 98.3 & 98.9 & 98.8 & 98.7 & 98.5 & 98.4 & 98.4 & 98.7 & 98.6 & 98.4 \\
\hline SSR Milk-Excluding Butter + & 77.2 & 78.8 & 80.4 & 78.9 & 77.0 & 79.8 & 79.7 & 80.4 & 80.0 & 79.3 \\
\hline SSR Fish, Seafood + & 73.1 & 67.5 & 65.8 & 60.7 & 53.3 & 56.4 & 56.2 & 57.9 & 54.8 & 54.0 \\
\hline SSR Aquatic Products, Other + & 92.6 & 92.6 & 90.9 & 86.5 & 85.9 & 83.9 & 83.9 & 84.7 & 82.4 & 83.0 \\
\hline
\end{tabular}




\begin{tabular}{|c|c|c|c|c|c|c|c|c|c|c|}
\hline & 2001 & 2002 & 2003 & 2004 & 2005 & 2006 & 2007 & 2008 & 2009 & 2010 \\
\hline SSR Cereals-Excluding Beer + & 20.7 & 20.5 & 18.7 & 21.0 & 21.7 & 20.5 & 21.1 & 21.9 & 19.9 & 20.0 \\
\hline SSR Starchy Roots + & 76.4 & 78.0 & 76.9 & 74.5 & 76.2 & 73.7 & 75.0 & 74.5 & 73.3 & 72.8 \\
\hline SSR Sugarcrops + & 100.0 & 100.0 & 100.0 & 100.0 & 100.0 & 100.0 & 100.0 & 100.0 & 100.0 & 100.0 \\
\hline SSR Sugar \& Sweeteners + & 55.7 & 56.2 & 57.1 & 57.5 & 57.6 & 58.8 & 56.5 & 58.9 & 60.1 & 58.5 \\
\hline SSR Pulses + & 34.7 & 36.2 & 30.0 & 44.6 & 40.8 & 32.8 & 34.8 & 36.5 & 28.1 & 32.6 \\
\hline SSR Treenuts + & 13.4 & 13.2 & 11.8 & 10.8 & 10.0 & 10.6 & 10.6 & 13.2 & 11.1 & 10.9 \\
\hline SSR Oilcrops + & 3.9 & 3.6 & 3.1 & 2.4 & 3.4 & 3.5 & 3.5 & 4.1 & 3.9 & 3.7 \\
\hline SSR Vegetable Oils + & 75.0 & 74.7 & 73.4 & 68.8 & 65.8 & 65.8 & 66.3 & 63.2 & 62.1 & 61.8 \\
\hline SSR Vegetables + & 80.8 & 82.2 & 81.0 & 79.1 & 78.5 & 79.5 & 81.2 & 82.7 & 83.2 & 80.5 \\
\hline SSR Fruits-Excluding Wine + & 52.2 & 47.5 & 46.2 & 41.9 & 42.9 & 40.7 & 41.8 & 43.3 & 44.6 & 40.8 \\
\hline SSR Stimulants + & 11.6 & 11.5 & 12.4 & 12.7 & 12.5 & 11.3 & 11.8 & 13.3 & 11.7 & 11.3 \\
\hline SSR Spices + & 13.2 & 19.6 & 17.8 & 21.8 & 23.6 & 23.5 & 26.4 & 28.4 & 34.0 & 34.6 \\
\hline SSR Alcoholic Beverages + & 94.4 & 93.8 & 93.4 & 93.2 & 93.2 & 85.9 & 93.4 & 85.5 & 83.6 & 81.7 \\
\hline SSR Meat + & 50.7 & 52.5 & 52.0 & 53.0 & 50.2 & 52.6 & 52.3 & 52.2 & 54.7 & 52.3 \\
\hline SSR Offals + & 66.6 & 72.8 & 70.3 & 86.4 & 85.0 & 85.3 & 84.0 & 84.3 & 83.9 & 82.5 \\
\hline SSR Animal Fats + & 65.0 & 71.9 & 71.6 & 72.3 & 70.7 & 72.3 & 74.0 & 70.6 & 79.2 & 76.2 \\
\hline SSR Eggs + & 98.4 & 98.2 & 98.4 & 98.3 & 97.0 & 98.1 & 98.5 & 98.5 & 98.7 & 98.7 \\
\hline SSR Milk-Excluding Butter + & 79.6 & 80.6 & 81.1 & 80.2 & 80.8 & 81.3 & 79.8 & 82.0 & 81.8 & 81.2 \\
\hline SSR Fish, Seafood + & 49.1 & 46.2 & 52.1 & 47.9 & 49.1 & 49.9 & 52.7 & 53.9 & 54.6 & 54.6 \\
\hline \multirow[t]{2}{*}{ SSR Aquatic Products, Other + } & 84.2 & 84.7 & 83.1 & 80.6 & 82.2 & 81.7 & 86.1 & 85.7 & 86.8 & 86.8 \\
\hline & 2011 & & & & & & & & & \\
\hline SSR Cereals-Excluding Beer + & 20.9 & & & & & & & & & \\
\hline SSR Starchy Roots + & 71.2 & & & & & & & & & \\
\hline SSR Sugarcrops + & 100.0 & & & & & & & & & \\
\hline SSR Sugar \& Sweeteners + & 53.7 & & & & & & & & & \\
\hline SSR Pulses + & 29.2 & & & & & & & & & \\
\hline SSR Treenuts + & 8.6 & & & & & & & & & \\
\hline SSR Oilcrops + & 3.9 & & & & & & & & & \\
\hline SSR Vegetable Oils + & 60.6 & & & & & & & & & \\
\hline SSR Vegetables + & 79.3 & & & & & & & & & \\
\hline SSR Fruits-Excluding Wine + & 40.1 & & & & & & & & & \\
\hline SSR Stimulants + & 10.6 & & & & & & & & & \\
\hline SSR Spices + & 34.2 & & & & & & & & & \\
\hline SSR Alcoholic Beverages + & 80.9 & & & & & & & & & \\
\hline SSR Meat + & 49.9 & & & & & & & & & \\
\hline SSR Offals + & 80.5 & & & & & & & & & \\
\hline SSR Animal Fats + & 75.3 & & & & & & & & & \\
\hline SSR Eggs + & 98.1 & & & & & & & & & \\
\hline SSR Milk-Excluding Butter + & 80.1 & & & & & & & & & \\
\hline SSR Fish, Seafood + & 54.6 & & & & & & & & & \\
\hline SSR Aquatic Products, Other + & 86.8 & & & & & & & & & \\
\hline
\end{tabular}

